\section{Muscling up in cancer cachexia}

\section{By Michael J. Haas, Senior Writer}

Researchers at Amgen Inc. and colleagues at Harvard Medical School have developed a soluble activin receptor type $2 \mathrm{~b}$ (ACVR2B) decoy that reversed muscle wasting and increased survival in mice with cancer cachexia. ${ }^{1}$ But targeting muscle loss alone is likely to be insufficient to treat cachexia because the indication involves myriad other symptoms.

Muscle wasting in cachexia is the primary cause of death in more than $20 \%$ of cancer patients. Studies have implicated multiple hormones, chemokines, cytokines, transcription factors and tumor-secreted factors in the pathogenesis of the muscle loss, but there is no consensus about the dominant underlying mechanism.

As a result, companies are developing a broad range of therapies to combat cachexia-related muscle loss. These include appetite enhancers, nonsteroidal selective androgen receptor modulators (SARMs) that mimic the anabolic effects of steroids, and inhibitors of cytokine or chemokine activity.

To find the key mechanism, the Amgen-led team focused on ACVR2B for two reasons. First, signaling between ACVR2B and its endogenous ligand myostatin (GDF-8) is known to inhibit muscle growth. The company's AMG 745 selective myostatin inhibitor already is in Phase I testing to treat muscle wasting in several undisclosed indications.

Second, multiple studies have found increased levels of another ACVR2B ligand, activin, in cancer patients, ${ }^{2-4}$ leading the team to speculate that activin-ACVR2B signaling might drive muscle wasting in some cancers.

Indeed, the Amgen and Harvard team found that of 16 human cancer cell lines, 6 produced large amounts of activin and 3 produced moderate amounts.

To test whether ACVR2B inhibition could treat cancer cachexia, the team engineered a soluble ACVR2B decoy that inhibited the receptor's interactions with both activin and myostatin.

In multiple mouse models-including those with activin-expressing xenograft tumors - the decoy reversed skeletal muscle loss and increased survival compared with vehicle. Notably, the decoy's effects were independent of tumor growth, fat loss or the production of proinflammatory cytokines.

The team, led by H.Q. Han, scientific executive director at Amgen, included Alfred Goldberg, professor of cell biology at Harvard Medical School. Data were reported in Cell. ${ }^{1}$

"We're thrilled that they published this paper, because it raises awareness of cancer cachexia" and shows that loss of muscle plays an important role in cachexia outcomes, Randall Schatzman, president and CEO of Alder Biopharmaceuticals Inc., told SciBX.

Alder's ALD518, a humanized mAb against IL-6, has completed Phase IIa testing to treat non-small cell lung cancer (NSCLC)-related fatigue and cachexia. The company expects to begin a Phase IIb trial early next year.

Irach Taraporewala, CEO of Ohr Pharmaceutical Inc., said the effects of ACVR2B inhibition on blocking muscle protein breakdown and stimulating new muscle growth provide "a means of mitigating the muscle mass loss that is one of the principal symptomatic features of cancer cachexia" without the potential androgenic side effects of anabolic steroids or steroid mimics.

Ohr's OHR118 (AVR118), a peptide nucleic acid-type immunomodulator that targets the activity of multiple chemokines and cytokines, is in Phase IIb testing to treat cancer cachexia.

\section{Reproduction issues?}

Despite the decoy's positive effects on muscle loss and survival, other companies working on cachexia wanted to know more about the safety of inhibiting ACVR2B.

The Cell paper "is a good proof-of-concept study for the efficacy of this approach, but the next logical step would be to conduct toxicological studies in mice or higher species to examine the effects of higher doses and longer-term use of the decoy" on tissues besides muscle, said James Dalton, VP of preclinical R\&D at GTx Inc.

GTx's ostarine (GTx-025), a nonsteroidal SARM, has completed Phase II testing to treat cachexia in patients with lung, colorectal or breast cancer.

Taraporewala noted that ACVR2B receptors are found in the CNS and play roles in spermatogenesis and embryogenesis. Thus, he said, "ACVR2B inhibition could have adverse effects on male and female fertility, and also produce adverse neurological effects."

Piet Wigerinck, SVP of development at Galapagos N.V., also wanted to know about the effects of blocking the activin-ACVR2B interaction on several activin-regulated hormonal pathways that play roles in human reproduction and fertility, including the testosterone and follicle stimulating hormone (FSH) pathways.

Galapagos' GLPG0492, an orally available nonsteroidal SARM, is in Phase I testing to treat cachexia and in preclinical development to treat Duchenne muscular dystrophy (DMD).

\section{Beyond brute strength}

If ACVR2B inhibition proves to be safe, it is unlikely that ACVR2B blockers would be effective as a stand-alone therapy to treat cachexia.

"The team's results are exciting in terms of the increase in lean mass and survival" and fit with published studies that link the two in cachexia, said John Friend, SVP of R\&D at Helsinn Healthcare S.A.'s Helsinn Therapeutics U.S. Inc. unit. "But cachexia is a complex metabolic condition, and the team's preclinical studies don't address its intricacies."

Taraporewala agreed, noting in particular that the soluble decoy in the Cell study had no effect on cytokine levels. As a result, he 


\section{ANALYSIS}

\section{TARGETS \& MECHANISMS}

told SciBX, it's unclear whether an ACVR2B inhibitor would affect the non-muscle loss components of cachexia such as anorexia and fatigue as well as associated gastrointestinal complications such as early satiety, bloating and cramping.

"The preponderance of evidence suggests that a large component of the biochemical abnormalities of cancer cachexia are cytokine and chemokine driven," he said. "Therefore, it is unlikely that an approach that does not involve any cytokine modulation would be effective in addressing the full spectrum of cachexia symptoms."

Alder CMO Jeffrey Smith also agreed.

"Muscle catabolism is an important component of cancer cachexia and has a critical effect on survival, but cancer cachexia per se is broader than just loss of muscle mass," he said. "We think that targeting inflammation via IL-6 inhibition is key because it can treat other symptoms besides muscle loss" such as chronic anemia, loss of appetite, fatigue and thrombotic tendencies.

He also noted that the ACVR2B inhibitor in the Cell article increased survival without reducing fat loss in the mouse models-a result that is probably not representative of what would happen in cancer cachexia patients. Indeed, published studies have linked higher body fat to greater survival in cancer patients, ${ }^{5,6}$ he said.

Added Smith: "If you lose $30 \%$ of your body mass-whether as muscle or fat-you're probably not going to survive."

Friend agreed. "It is not clear to cachexia researchers which is more significant to overall survival in humans-muscle loss or fat loss-but both probably play a role," he said.

Helsinn's Anamorelin, a small molecule ghrelin mimetic, has completed four Phase II trials to treat cachexia in patients with various cancers.

Taraporewala did suggest that combining ACVR2B inhibition with chemokine or cytokine modulation "could be potentially advantageous in stopping and/or reversing the cancer cachexia disease process-if a synergistic effect can be demonstrated."
Schatzman also said combining inhibitors of IL- 6 and ACVR2B could be beneficial but cautioned that future studies would have to elucidate the precise-and probably complex-relationship between the two proteins in different tissues.

"We would argue that IL-6 operates upstream of the activin receptor, but studies in the literature suggest that IL- 6 activity may also occur downstream of ACVR2B depending on the tissue type," he said.

Amgen declined to disclose its development plans for the ACVR2B decoy. Han did say the company is interested in investigating whether ACVR2B inhibition could also treat muscle wasting due to cachexia in noncancer indications such as AIDS, congestive heart failure (CHF), chronic kidney disease (CKD), muscular dystrophy and age-related sarcopenia.

Amgen holds multiple patents that cover inhibition of the ACVR2B signaling pathway.

Haas, M.J. SciBX 3(35); doi:10.1038/scibx.2010.1057

Published online Sept. 9, 2010

\section{REFERENCES}

1. Zhou, X. et al. Cell; published online Aug. 19, 2010; doi:10.1016/j.cell.2010.07.011

Contact: H.Q. Han, Amgen Inc., Thousand Oaks, Calif. e-mail: hqhan@amgen.com

2. Otani, T. et al. Gynecol. Oncol. 83, 31-38 (2001)

3. Wildi, S. et al. Gut 49, 409-417 (2001)

4. Seder, C.W. et al. Neoplasia 11, 388-396 (2009)

5. Kalantar-Zadeh, K. et al. Curr. Opin. Clin. Nutr. Metab. Care 10, 433-442 (2007)

6. Lundholm, K. et al. Clin. Cancer Res. 13, 2699-2706 (2007)

COMPANIES AND INSTITUTIONS MENTIONED

Alder Biopharmaceuticals Inc., Bothell, Wash. Amgen Inc. (NASDAQ:AMGN), Thousand Oaks, Calif. Galapagos N.V. (Euronext:GLPG; Pink:GLPYY), Mechelen, Belgium GTx Inc. (NASDAQ:GTXI), Memphis, Tenn. Harvard Medical School, Boston, Mass. Helsinn Healthcare S.A., Pazzallo, Switzerland Ohr Pharmaceutical Inc. (OTCBB:OHRP), Salt Lake City, Utah 